\title{
Analysis of Differential-expressed Proteins of Acidithiobacillus ferrooxidans Grown under Phosphate Starvation
}

\author{
Zhiguo He ${ }^{\dagger}$, Hui Zhong", Yuehua Hu${ }^{\dagger, *}$, Shengmu Xiao ${ }^{\dagger}$, Jiarshe Liu ${ }^{\dagger}$, Jin $\mathrm{Xu}^{\dagger}$ and Guiyuen $\mathrm{Li}^{\ddagger}$ \\ 'School of Resources Processing and Bioengineering, Central South University, Changsha, P. R. China \\ Cancer Research Institute, Central South University, Changsha, P. R. China
}

Received 14 April 2005, Accepted 2 June 2005

\begin{abstract}
Acidithiobacillus ferrooxidans is one of the most important bacterium used in bioleaching, and can utilize $\mathrm{Fe}^{2+}$ or sulphide as energy source. Growth curves for Acidithiobacillus ferrooxidans under phosphate starvation and normal condition have been tested, showing lag, logarithmic, stationary and aging phases as seen in other bacteria. The logarithmic phases were from 10 to 32 hours for Acidithiobacillus ferrooxidans cultivated with normal cultivating condition and from 20 to 60 hrs for Acidithiobacillus ferrooxidans cultivated phosphate starvation. Differences of protein patterns of Acidithiobacillus ferrooxidans growing in case of normal or phosphate starvation were separately investigated after cultivation at $3^{\circ} \mathrm{C}$ by the analysis of two-dimensional gel electrophoresis (2-DE), matrix-assisted laser desorption/ionization (MALDI)Mass spectrometry. There were total 6 protein spots identified, which were Recombination protein recA, RNA helicase, AP2 domain-containing transcription factor, NADH dehydrogenase I chain $D$, Hyothetical protein PF1669, and Transaldolase STY3758. From the 6 identified protein spots, 3 proteins were found to be decreased in expression at the cultivating condition of phosphate starvation, while another three upregulated.
\end{abstract}

Keywords: Acidithiobacillus ferrooxidans, MALDI-TOF/ MS, Phosphate starvation, Proteomics, Two-dimensional gel electrophoresis

\section{Introduction}

Microbes display a remarkable ability to adapt to environmental change. Specific environmental changes are often detected via

\footnotetext{
*To whom correspondence should be addressed.

Tel: 86-731-8879815; Fax: 86-731-8879815

E-mail: hzgcsu@126.com
}

biochemical signals, and in many cases these lead to the activation of specific physiological responses that counteract the original environmental changes. Acidithiobacillus ferrooxidans is a chemolithotrophic microorganism capable of using ferrous ions and reduced sulfur compounds as energy sources (Brierley, 1978). This microorganism has an important role in the bioleaching of minerals (Rojas-Chapana et al., 1996; Tributsch et al., 1998). During this process, the bacteria are normally subjected to several stressing conditions, such as temperature changes, lack of nutrients or $\mathrm{pH}$ changes, which may affect the efficiency of the bacterial action.

In this report, we focus on the proteome response of Acidithiobacillus ferrooxidans to phosphate starvation. This information might be helpful to understand the mechanisms of Acidithiobacillus ferrooxidans in different extreme conditions.

\section{Materials and Methods}

Strains and growth conditions Acidithiobacillus ferrooxidans isolated from Chengmenshan Mine, China, which then was cultured in $9 \mathrm{~K}$ base medium additionally adding $\mathrm{Fe}^{2+}$ or phosphate starvation respectively as energy resource at $30^{\circ} \mathrm{C}$ (Amaro et al., 1999). The $\mathrm{pH}$ of $9 \mathrm{~K}$ basic medium was adjusted to 2.0 with $2 \mathrm{~N}$ $\mathrm{H}_{2} \mathrm{SO}_{4}$. The reactors were 500-ml Erlenmeyer flasks mounted to a HZQ-C constant temperature vibrator agitated at $200 \mathrm{rpm}$, and the initial liquid volume of each reactor was $200 \mathrm{ml}$. Sterility was ensured by autoclaving the flasks and liquid solutions at $121^{\circ} \mathrm{C}$ for $25 \mathrm{~min}$, covering the opening with cotton plugs. Bioreactors were confirmed to maintain dissolved $\mathrm{O}_{2}$ concentrations in excess of $6 \mathrm{mg} /$ liter during the experimented periods. The number of cells was counted in a Helber chamber.

Preparation of protein extracts When the culture reached the later exponential phase of growth, it was centrifuged at $5,000 \times \mathrm{g}$ for $10 \mathrm{~min}$, and the bacterial sediment was firstly washed three times with the same basic culture medium without ferrous ions, then (from $1,000 \mathrm{~mL}$ of culture) were washed three times with icecold water and resuspended in $50 \mu \mathrm{L}$ of $7.5 \mathrm{M}$ urea, $2.5 \mathrm{M}$ thiourea, 
$1.25 \mathrm{mM}$ EDTA, $1.75 \mathrm{mg} / \mathrm{mL}$ Pepstatin A, protease inhibitor cocktail. Cells were disrupted by sonicatted with a sonicater six times for $30 \mathrm{~s}$ with $1 \mathrm{~min}$ on ice in between. Samples were vortexed thoroughly, and shaken. Cell debris were removed by centrifugation at 10,000 $\times g$ for $10 \mathrm{~min}$ at $4^{\circ} \mathrm{C}$, and the resulting supernatant stored at $-70^{\circ} \mathrm{C}$. Protein concentration was measured according to the method of Lowery et al. (Lowry, 1951).

Two-dimensional ampholyte gel electrophoresis 2-DE was performed according to the method of Kim et al. (2001) About $450 \mu \mathrm{g}$ of protein were loaded in triplicate on Immobiline. Dry Strip gels (180 mm, pH3-10 and pH 4-7 linear; Amersham Biosciences, Richmond, USA) and run on an Ettan. IPGphor isoelectric focusing unit (Amersham Biosciences) for 57,900 Vh. SDS-PAGE in the second dimension was carried out as described by Laemmli (1970), Precast SDS $12.5 \%$ polyacrylamide gels (Amersham Biosciences) were used for the second dimension (initially run for $1 \mathrm{~h}$ at $30 \mathrm{~W}$, then for $4.5 \mathrm{~h}$ at $180 \mathrm{~W}$, for a set of 2 gels) using an Ettan DALT System (Amersham Biosciences). The 2-DE gels were silver stained by the method of Blum et al. (1987).

Image analysis Triplicate gels were scanned using a Hewlitt Packard Scanjet 5370C, and the images analysed using Progenesis and Phoretix 2D software (Nonlinear Dynamics, Newcastle-uponTyne, UK) to identify features that were reproducibly up-regulated or down-regulated. Spot volumes were normalised against total spot volume and total spot area. Features that displayed statistically significant changes in mean normalised spot volume on at least two out of three replicate gels ( $p<0.05$; Student's $t$-test) were excised for protein identification.

Protein identification by peptide mass fingerprinting All mass spectra of MALDI-TOF-MS were obtained on a Bruker REFLEX III MALDI-TOF-MS (Bruker-Franzen, Bremen, Germany) in positive ion mode at an accelerating voltage of $20 \mathrm{kV}$ with the matrix of A-cyano-4-hydroxy cinnamic acid. The spectra were internally calibrated using trypsin autolysis products. PMF obtained was used to search through the SWISS-PROT and NCBInr database by the Mascot search engine (http://www.matrixscience.co.uk) with a tolerance of 7B $0.1 \mathrm{D}$ and one missed cleavage site.

\section{Results}

The measurement of growth curves for Acidithiobacillus ferrooxidans To explore the growth characteristics of Acidithiobacillus ferrooxidans for the purpose of performing the comparative proteome analysis of this organism, the growth curves of Acidithiobacillus ferrooxidans were dertermined and shown in Fig. 1. It can be seen that two growth curves followed the same lag, logarithmic, stationary and aging phase as seen in other bacteria. The logarithmic phase was from 10 to $32 \mathrm{hrs}$ for Acidithiobacillus ferrooxidans cultivated with normal condition and from 20 to $60 \mathrm{hrs}$ for Acidithiobacillus ferooxidans cultivated without phosphate. When Acidithiobacillus ferrooxidans cultivated with $\mathrm{Fe}^{2+}$ for bout $36 \mathrm{hrs}$, the number of cells would reach the highest
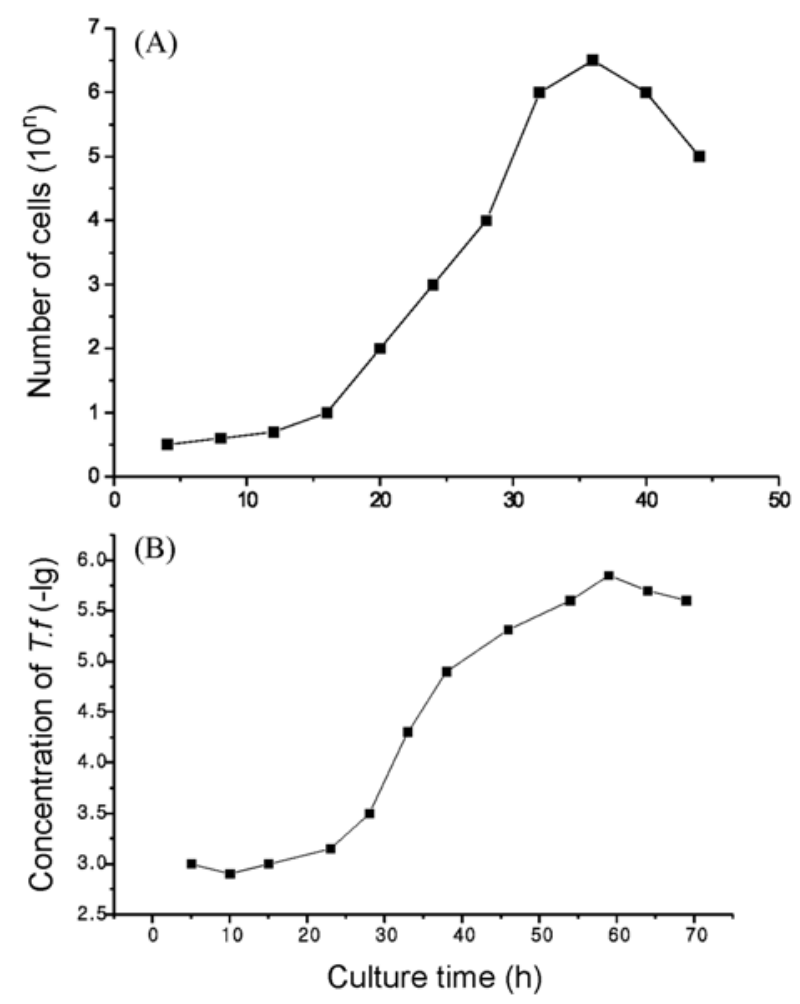

Fig. 1. Growth kinetics of Acidithiobacillus ferrooxidans cultured with phosphate and phosphate starvation separately. (A) grown normal condition additionally adding $\mathrm{Fe}^{2+}$ as energy resource; (B) under phosphate starvation additionally adding $\mathrm{Fe}^{2+}$ as energy resource.

(about $1 \times 10^{6.5}$ cells/l). While Acidithiobacillus ferrooxidans grew under phosphate starvation, the lag phase was greatly longer than that of Acidithiobacillus ferrooxidans grown with $\mathrm{Fe}^{2+}$, and the number of cells reached maximum (about $1 \times 10^{5.5}$ cells $/ \mathrm{ml}$ ) after 60 hrs' cultivation.

Two-dimensional proteome maps identify changes in protein expression of Acidithiobacillus ferrooxidans grown with $\mathrm{Fe}^{2+}$ and phosphate starvation separately Before study proteome response of Acidithiobacillus ferrooxidans to phosphate starvation, we established common and reproducible procedures for protein extraction from these microbial and the analysis of these extracts by 2-DE. The rationale was that the use of common procedures would allow a more robust comparison of the Acidithiobacillus ferrooxidans cultivated under normal condition and phosphate starvation separately. To identify changes in protein expression in response to phosphate starvation, we compared proteome of Acidithiobacillus ferrooxidans growing with phosphate starvation with proteome of Acidithiobacillus ferrooxidans growing under normal condition. Cells were collected at later halflogarithmic respectively, and Cell lysates were resolved by 2DE. We reproducibly detected about 630 protein spots after silver staining (Fig. 2). We ran and analyzed at least three gels for each experimental condition. 

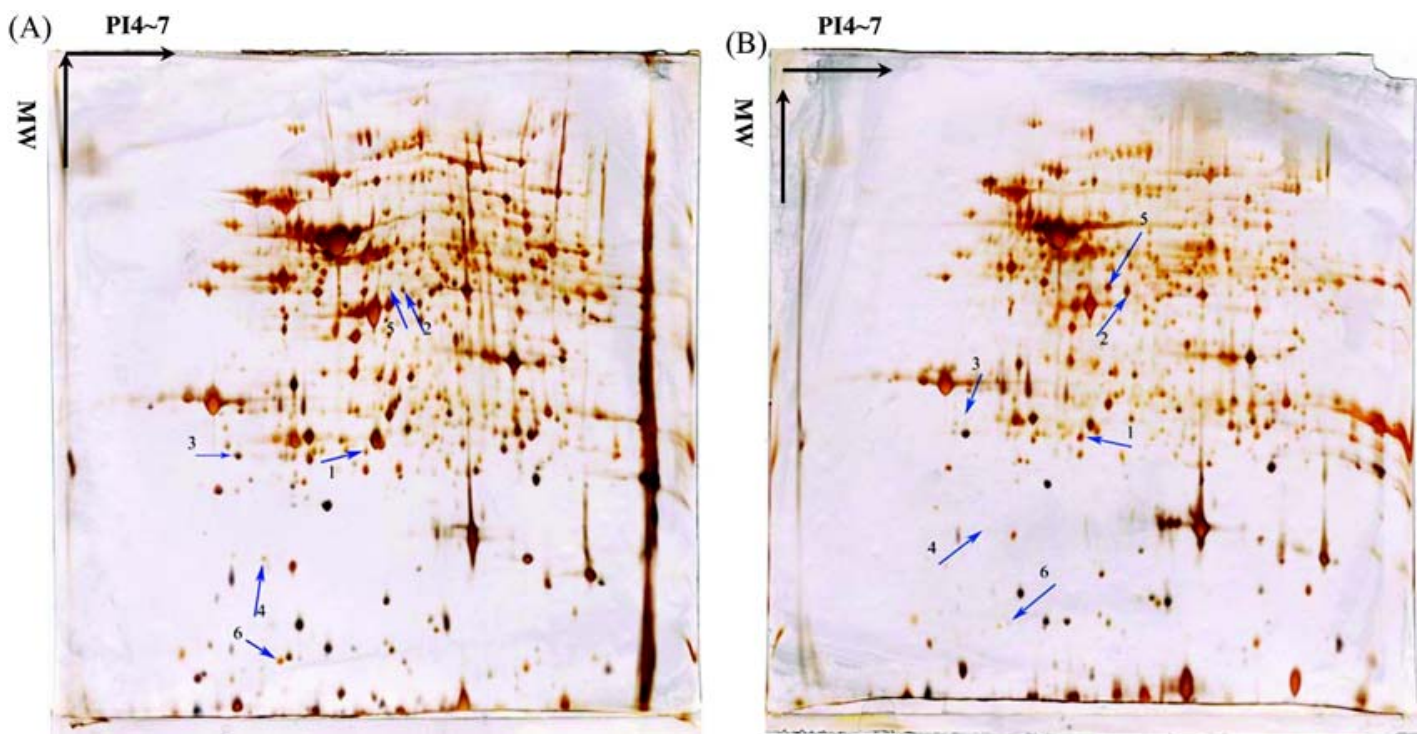

Fig. 2. (A) 2-D SDS-PAGE of proteins isolated from cells of Acidithiobacillus ferrooxidans grown on $9 \mathrm{~K}$ base medium adding Fe ${ }^{2+}$, and the PI's range for try strip was $\mathrm{pH} 4-7$; The amount of protein loaded was $450 \mu \mathrm{g}$. (B) 2-D SDS-PAGE of protein isolated from cells of Acidithiobacillus ferrooxidans grown on under phosphate starvation additionally adding $\mathrm{Fe}^{2+}$ as energy resource, and the PI's range for try strip was $\mathrm{pH} 4-7$; The amount of protein loaded was $450 \mu \mathrm{g}$.

Table 1. Identified Acidithiobacillus ferrooxidans proteins that were regulated by phosphate starvation manner

\begin{tabular}{|c|c|c|c|c|c|c|c|c|}
\hline spot & Protein name & $\begin{array}{l}\text { NCBI } \\
\text { ID no. }\end{array}$ & MASS & $\begin{array}{c}\mathrm{Mr} \\
(\mathrm{kDa})\end{array}$ & $\mathrm{pI}$ & $\begin{array}{c}\text { Sequence } \\
\text { coverage }(\%)\end{array}$ & Score & $\begin{array}{l}\text { Protein } \\
\text { expression }\end{array}$ \\
\hline No. 1 & Recombination protein rec $\mathrm{A}$ & JC1377 & MALADI-TOF-MS & 38.892 & 5.24 & 32 & 72 & $\uparrow$ \\
\hline No. 2 & RNA helicase & Gi 42522889 & MALADI-TOF-MS & 51.154 & 9.69 & 35 & 72 & $\uparrow$ \\
\hline No. 3 & $\begin{array}{l}\text { AP2 domain-containing } \\
\text { transcription factor }\end{array}$ & Gi|15238816 & MALADI-TOF-MS & 34.782 & 5.10 & 31 & 72 & $\downarrow$ \\
\hline No. 4 & NADH dehydrogenase I chain D & Gi|15892405 & MALADI-TOF-MS & 48.37 & 5.90 & 31 & 75 & $\downarrow$ \\
\hline No. 5 & Hyothetical protein PF1669 & Q8UODO & MALADI-TOF-MS & 66.16 & 7.96 & 43 & 71 & $\uparrow$ \\
\hline No. 6 & Transaldolase STY3758 & AG0936 & MALADI-TOF-MS & 23.609 & 5.14 & 59 & 71 & $\downarrow$ \\
\hline
\end{tabular}

a) Expression ratio was calculated relative to protein levels in untreated wild-type cells. The expression ratio for " unique "spots" only detected under one condition was calculated by dividing the normalized peak volume by the lowest detectable normalized volume. The " $\uparrow$ " indicates the amount of protein expressed under phosphate starvation is greater than under normal condition additionally adding $\mathrm{Fe}^{2+}$ as energy resource; conversely “ $\downarrow$ ” indicate the protein expression was downregulated under phosphate starvation.

From the gels, we noticed most of the spots shown in Fig. 2 were distributed in PI 5-7 and their molecular mass ranged 10$140 \mathrm{kD}$. The 12 spots selected, which were obviously changed in their expression in response to phosphate starvation, were subjected to in-gel trypsin digestion and analysis with matrix-assisted laser desorption/ionization time-of-flight mass spectrometry (MALDI-TOF-MS) (Table 1). As a result, 6 protein spots identified. Among the 6 protein spots identified, 3 spots were found more abundant when growing with phosphate starvation, while 3 decreased under this condition. results identified by peptide mass fingerprinting (PMF) were evaluated by MOSCOW values and sequence coverage.

From a differential expression protein spot1 highlighted from three pares of gels, We found that the amount of this protein expressed when Acidithiobacillus ferrooxidans growing under phosphate starvation is about five times of expressed when growing on normal condition in each parallel experiment (As shown in Fig. 3: a compared with b; c compared with d; e compared with f), which indicated excellent reproducible results in our work. The differential expressed protein spots identified by MALDI-TOF-MS (as show in Table 1) included Recombination protein recA, RNA helicase, AP2 domain-containing transcription factor, NADH dehydrogenase I chain D, Hyothetical protein PF1669, and Transaldolase STY3758, while the other protein spots which were unable to be identified are due to the incomplete genomic sequencing of Thiobacillus ferrooxidans.

\section{Discussion}

As a necessary nutrient element for Acidithiobacillus 
(A)

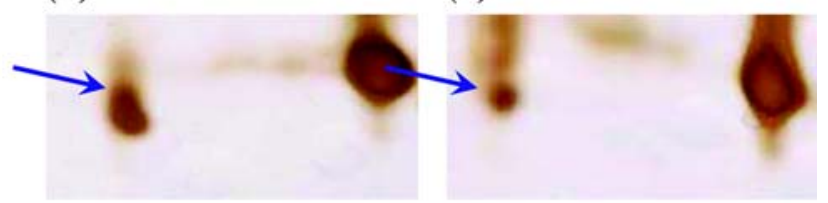

(C)

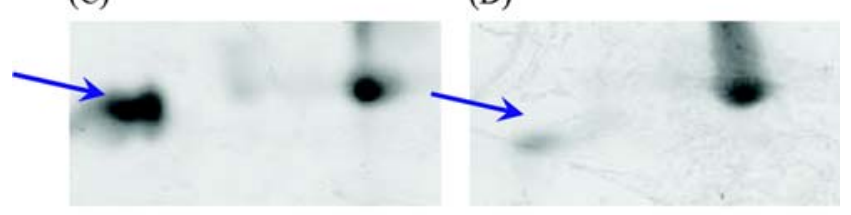

(E)

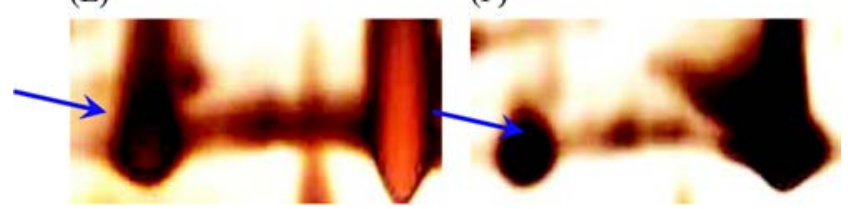

Fig. 3. A reproducible expression change in the Acidithiobacillus ferrooxidans proteome that occurs in response to different cultivating condition. The highlighted protein is one differential expressed protein spot. (A), (C) and (E) are Acidithiobacillus ferrooxidans cultivated under the condition of phosphate starvation; (B), (D), and $(\mathrm{F})$ are Acidithiobacillus ferrooxidans cultivated with normal condition with $\mathrm{Fe}^{2+}$ as energy source.

ferrooxidans' growth, the starvation of phosphate will greatly influence the bioleaching activity of Acidithiobacillus ferrooxidans. Jerez et al. (Guiliani, 2000; Jerez et al., 1992) found a out-membrane protein Omp40 was differentially expressed under phosphate starvation. M. Vera et al. (2003) found the expression of PstS was markably increased when Acidithiobacillus ferrooxidans grown under phosphate starvation and anchored its position. There were two PstS-analogous genes in Acidithiobacillus ferrooxidans, each of which had a putative signal peptide, indicating that PstS-encoded protein might be located at cytoplasm. In this study, by adopting comparative proteomics methods, we also found another several differentially expressed proteins, which included Recombination protein recA, RNA helicase, AP2 domaincontaining transcription factor, NADH dehydrogenase I chain D, Hyothetical protein PF1669, Transaldolase STY3758. We have also identified 17 differentially expressed proteins of Acidithiobacillus ferrooxidans which grown taking $\mathrm{Fe}^{2+}$ or elemental sulfur as energy resource respectively (Zhiguo et al., 2005). But these proteins showed no obvious differentially expressed when Acidithiobacillus ferrooxidans grown under phosphate starvation.

NADH dehydrogenase plays an important role in the process of cellular Oxidative Phosphorylation and Photophosphorylation. In the aerobic organisms, although the degradations of carbohydrates, fats, and amino acids via respect degrading routes, they all share a common process of oxidation, in which carbohydrates, fats, and reductive coenzyme (NADH and $\mathrm{FADH}_{2}$ ) formed from the dehydration of amino acids will
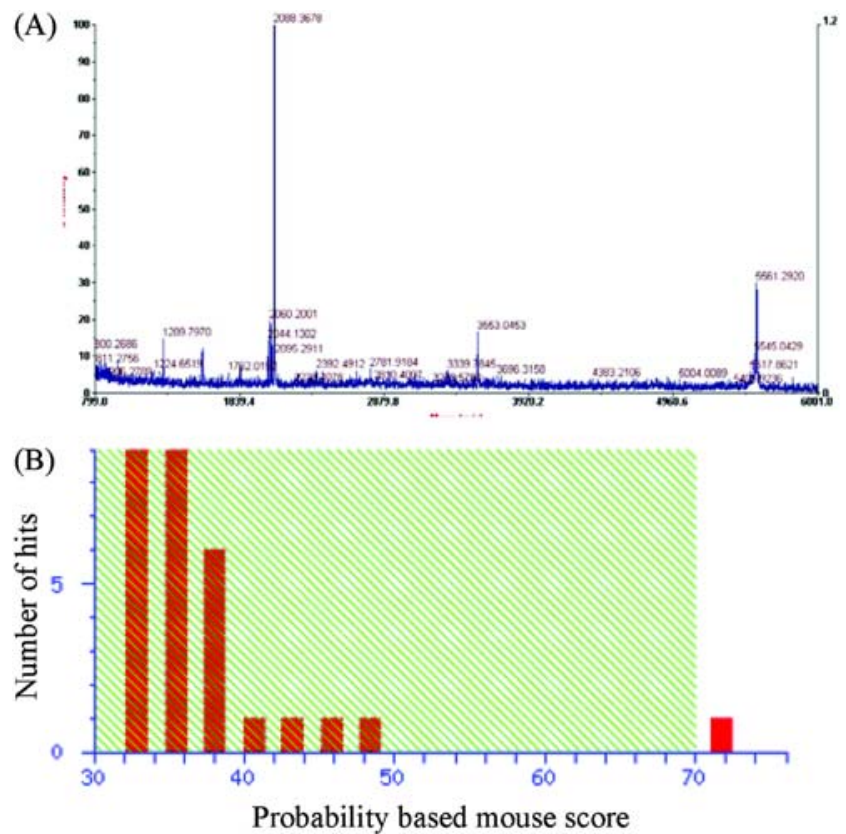

Fig. 4. Analysis of differently expressed No. 1 protein and the masses indicated were matched to Recombination protein recA. a: MALDI-TOF-MS spectra obtained for Recombination protein recA. Monoisotopic peptides were used to search protein databases to match and subsequently identify individual protein spots. The 2211.7792 were is a trypsin auto-digestion peptide used for mass calibration. b: Probability Based Mowse Score. Score is $-10^{*} \log (\mathrm{P})$, where $\mathrm{P}$ is the probability that the observed match is a random event. Protein scores greater than 71 are significant $(p<0.05)$.

transfer electrons and $\mathrm{H}^{+}$along electrotransporting chains to oxygen and form molecular $\mathrm{H}_{2} \mathrm{O}$ ultimately (Ravishankar et $a l ., 2005)$. In this processes, the free energy released was used to form ATP by ADP and Pi. This total process was Oxidative Phosphorylation. Some important reactions catalyzed by NADPH-linked Dehydrogenase are shown as following.

Glucose 6-phosphate+NADP ${ }^{+} \rightarrow$ 6-phosphogluconate+NADPH+H ${ }^{+}$ L-Glutamate $+\mathrm{H}_{2} \mathrm{O}+\mathrm{NADP}^{+} \rightarrow \alpha$-ketoglutarate $+\mathrm{NH}_{4}{ }^{+}+\mathrm{NADPH}$ Isocitrate $+\mathrm{NADP}^{+} \rightarrow \alpha$-ketoglutarate $+\mathrm{CO}_{2}+\mathrm{NADPH}+\mathrm{H}^{+}$

Our research found that when Acidithiobacillus ferrooxidans cultivated under phosphate starvation, the expression of NADH dehydrogenase I chain D was lower than that of cultivated with normal condition. This may due to the inefficient of phosphate which put phosphorus-consuming reaction like Oxidative Phosphorylation unable to carry through, so the amount of expressed NADH dehydrogenase was degreased. We can also easily found from the growth curve of Acidithiobacillus ferrooxidans cultivated under phosphate starvation that, the activity of bacteria was inhibited (as shown in Fig. 1).

Transaldolase plays an important role in Pentose Phosphate Pathway. Two enzymes unique to the pentose phosphate pathway act in these interconversions of sugars: transketolase 
and transaldolase. Transaldolase catalyzes a reaction similar to the aldolase reaction of glycolysis: a three-carbon fragment is removed from sedoheptulose 7-phosphate and condensed with glyceraldehyde 3-phosphate, forming fructose 6-phosphate and the tetrose erythrose 4-phosphate. We found that when Acidithiobacillus ferrooxidans grown under phosphate starvation, the level of expression for Transaldolase was downregulated, and the real mechanism need for further research. $\operatorname{Rec} A$ is known to be growth rate dependent in other bacteria, in our study, we also found $\operatorname{Rec} A$ was upregulated under phosphate starvation.

It has been discovered that RNA helicase is a calciumregulated protein. Being a exoribonuclease, RNA helicase can break up alkali pairs and the interaction between RNA and proteins. Additionally, as one of the key components of exosome, RNA helicase takes part in the degradation of inproperly scissored or none-PolyA's pre-mRNA. In this study, we found that when Acidithiobacillus ferrooxidans grown under phosphate starvation, the expression of RNA helicase was upregulated.

$\mathrm{AP}_{2}$ domain was once considered peculiar for plant. But recent research work found that there also contained transcription factor containing $\mathrm{AP}_{2}$ domain in some protokaryotics. Xue et al. (2002) found that a $\mathrm{AP}_{2}$ domaincontaining transcription factor in barley's leaves would be induced to express under low temperature condition, while not to express when drought or treated with abscisic acid (ABA). It involved many mechanisms for bacteria to deal with the biologic and abiotic intimidating conditions. One important aspect is the transcript activity or gene's inhibition. Our experiments discovered that, when Acidithiobacillus ferrooxidans was cultivated at the condition of phosphate starvation, the expression of transcript factors containing $\mathrm{AP}_{2}$ domain would obviously be downregulated, which might give us some information for further elucidating the mechanisms how Acidithiobacillus ferrooxidans adapt to intimidating condition such as phosphate starvation, hitemperature et al..

Acknowledgment This work was supported by Chinese Science Foundation for Distinguished Group (No. 50321402), National Basic Research Program (973 Program) of P. R. China (No. 2004CB619204), and Chinese Natural Science Foundation (No. 30400010).

\section{References}

Amaro, A. M., Chamorro, D., Seeger, M., Arredondo, R., Peirano,
I. and Jerez, C. A. (1999) Effect of external pH perturbations on in vivo protein synthesis by the acidophilic bacterium Acidithiobacillus ferrooxidans. J. Bacteriol. 173, 910-915.

Blum, H., Beier, H. and Gross, H. J. (1987) Improved silver staining of plant proteins, RNA and DNA in polyacrylamide gels. Electrophoresis 8, 93-99.

Brierley, C. L. (1978) Bacterial leaching. Crit. Rev. Microbiol. 6, 207-262.

Guiliani, N. and Jerez, C. A. (2000) Molecular cloning, sequencing, and expression of omp-40, the gene coding for the major outer membrane protein from the acidophilic bacterium Thiobacillus ferrooxidans. Appl. Environ. Microbiol. 66, 23182324.

Jerez, C. A., Seeger, M. and Amaro, A. M. (1992) Phosphate starvation affects the synthesis of outer membrane proteins in Thiobacillus ferrooxidans. FEMS Microbiol. Lett. 77, 29-33.

Kim, S. T., Cho, K. S., Jang, Y. S. and Kang, K. Y. (2001) Twodimensional electrophoretic analysis of rice proteins by polyethylene glycol fractionation for protein arrays. Electrophoresis 22, 2103-2109.

Laemmli, U. K. (1970) Cleavage of structural proteins during the assembly of the head of bacteriophage T4. Nature 227, 680685.

Lowry, O. H., Rosebrough, N. J., Farr, A. L. and Randall, R. J. (1951) Protein measurement with folin phenol reagent. J. Biol. Chem. 193, 265-275.

Vera, M., Guiliani, N. and Jerez., C. A. (2003) Proteomic and genomic analysis of the phosphate starvation response of Acidithiobacillus ferrooxidans. Hydrometallurgy 71, 125-132.

Ravishankar, S., Kumar, V. P., Chandrakala, B., Jha, R. K., Solapure, S. M. and de Sousa, S. M. (2005) Scintillation proximity assay for inhibitors of Escherichia coli MurG and, optionally, MraY. Antimicrob. Agents Chemother. 49, 14101418.

Rojas-Chapana J. A., Giersig, M. and Tributsch, H. (1996) The path of sulfur during the bio-oxidation of pyrite by Thiobacillus ferooxidans. Fuel. 75, 923-930.

Tributsch, H., Rojas-Chapana, J. A., Bartels, C. C., Ennaoui, A. and Hofmann, W. (1998) Role of transient iron sulfide films in microbial corrosion of steel. Corrosion. 54, 216-227.

Xue, G. P. (2002) An AP2 domain transcription factor HvCBF1 activates expression of cold-responsive genes in barley through interaction with a $(\mathrm{G} / \mathrm{a})(\mathrm{C} / \mathrm{t}) \mathrm{CGAC}$ motif. Biochim. Biophys. Acta 1577, 63-72.

Zhiguo, H., Yuehua, H., Hui, Z., Weixin, H. and Jin, X. (2005) Preliminary proteomic analysis of Thiobacillus ferrooxidans growing on elemental sulphur and $\mathrm{Fe}^{2+}$ separately. J. Biochem. Mol. Biol. 38, 307-313. 